\title{
Sex hormones, glucocorticoids and autoimmunity: facts and hypotheses
}

\author{
José António P Da Silva
}

Increasing knowledge on the regulation of immune responses over the past decade has made it clear that the immune system is involved in complex interactions with most, if not all, of the biological systems responsible for normal homeostasis. The evidence for important interplays between the immune and endocrine systems has launched the whole new field of neuroimmunoendocrinology which has attracted the interest of scientists and clinicians alike. The mechanisms involved in the interactions between adrenal and gonadal steroids and the immune system are poorly understood, however, and further clarification could have important implications in the understanding of the pathogenesis and treatment of autoimmune diseases.

\section{Gender dimorphism in immune responses}

Human and experimental autoimmune diseases present marked gender differences. In humans, females are more commonly affected, with a female to male ratio that varies widely: $2-4: 1$ in rheumatoid arthritis, 5-13:1 in systemic lupus erythematosus, 3:1 in scleroderma, 9:1 in Sjögren's syndrome, 4-8:1 in Graves' disease. ${ }^{12}$ Similar gender related differences in susceptibility to autoimmune diseases are observed with a large number of experimental models, ${ }^{3}$ and are attributed to the well established gender dimorphism in immune responses-a subject that has been object of increasing interest over recent years, reflected in a number of excellent reviews. ${ }^{3-5}$ Overall, females have stronger humoral and cellular immune responses than males. Female animals from different species have higher serum concentrations of immunoglobulins ${ }^{6}$ and show a greater and more sustained production of antibodies after immunisation and infection. ${ }^{17}$ Cell mediated immune responses are also stronger in females, as demonstrated by a more efficient rejection of allografts ${ }^{8}$ and relative resistance to immunotolerance. ${ }^{9}$

Sex hormones play a central role in this gender dimorphism. Gender differences in antibody production become apparent only after sexual maturity ${ }^{10}$ and are greatly reduced by gonadectomy. ${ }^{11}$ Oestrogens have been shown to stimulate the $B$ cell response, while both androgens and progesterone depress it. ${ }^{12} 13$ Skin graft rejection time is reduced by gonadectomy in both male and female mice, ${ }^{8}$ while treatment with oestrogens, androgens, and progesterone results in delayed transplant rejection and depressed tumour-associated immunity in animals and humans. ${ }^{13-15} \mathrm{~A}$ thorough discussion of the vast evidence for immunomodulatory effects of sex steroids in both animals and humans can be found in the reviews cited above. Overall, oestrogens depress $\mathrm{T}$ cell mediated and stimulate $\mathrm{B}$ cell mediated immune responses, while progesterone and androgens depress both components of the immune system. ${ }^{3}$

There are a few experimental examples of gender differences in autoimmune diseases which are dependent, not on sex hormones, but on sex chromosome linked immune mechanisms. The male BXSB mouse susceptibility to lupus like disease is related to the $\mathrm{Y}$ chromosome linked 'autoimmune accelerating' yaa gene which is, intriguingly, capable of suppressing collagen induced arthritis, another model of autoimmune disease. ${ }^{16}$

The pathogenic relevance of the immune effects of sex steroids is illustrated by their influence on experimental and human autoimmune diseases. Androgens reduce and oestrogens enhance the incidence and severity of experimental murine lupus. ${ }^{17}{ }^{18}$ Similarly, in human SLE, oral contraceptives have been associated with disease exacerbation, ${ }^{19}$ whereas the androgen analogue danazol offers some degree of benefit. ${ }^{20}$ Orchidectomy increases and androgens decrease the susceptibility of male rats to autoimmune thyroiditis, ${ }^{21}$ whereas administration of oestrogen increases the production of antibodies against injected thyroglobulin. ${ }^{22}$ Androgens were also shown to reduce the incidence of autoimmune haemolytic anaemia in mice ${ }^{23}$ and rats, ${ }^{24}$ and to decrease the severity of experimental Sjögren's syndrome-like lesions in mice. ${ }^{25}$ The relative resistance of male Lewis LEW/N rats to streptococcal cell wall induced arthritis is abolished by castration and treatment with oestradiol. ${ }^{26}$ Interestingly, oestrogens have beneficial effects in a number of $\mathrm{T}$ cell dependent experimental diseases such as collagen induced arthritis, ${ }^{27}$ adjuvant induced arthritis, ${ }^{28}$ and experimental autoimmune encephalitis. ${ }^{29}$

We have recently performed a series of studies on the effects of sex hormones using an in vivo model of inflammation induced cartilage degradation in $\mathrm{BALB} / \mathrm{c}$ mice. This model allows the quantitation of cartilage destruction by juxtaposed cotton-induced granulomatous tissue, the development of which is $\mathrm{T}$ cell dependent. ${ }^{30}{ }^{31} \mathrm{We}$ have demonstrated that female mice degrade cartilage faster than males and that gonadectomy was 
associated with accelerated cartilage destruction in both males and females, demonstrating a protective role for sex hormones in both sexes. $^{32}$ Oestrogen replacement in castrated females completely reversed the effects of ovariectomy and treatment with physiological concentrations of androgens resulted in significant cartilage protection in both castrated males and females. Beneficial effects of sex hormones were also recently reported in human rheumatoid arthritis (RA), both with oestrogen replacement in postmenopausal women ${ }^{33}$ and with androgen therapy in male patients. ${ }^{34}$

In summary, females have a stronger immune reactivity than males which is translated in a higher susceptibility to a variety of autoimmune diseases. Decrease in circulating androgens as a result of orchidectomy increases male susceptibility, an effect reversed by androgen administration. Oestrogens, in contrast, can enhance autoantibody production, thereby increasing the severity of diseases depending on B cell hyperactivity, but they have also been shown to suppress experimental diseases mediated by $\mathrm{T}$ cells.

The mechanisms involved in sex hormone interaction with the immune system are complex and poorly understood. ${ }^{5} 35$ In vitro studies have demonstrated the potential for direct effects of sex hormones on immunocompetent cells. Oestrogens have been shown to suppress mitogen and antigen induced stimulation of $T$ cells and depress $T$ cell suppressor activity. ${ }^{12} 1536$ Testosterone and progesterone inhibit mitogen induced lymphocyte proliferation and enhance $T$ cell suppressor activity. ${ }^{37-39}$ Sex hormones have also been shown in vitro to modulate the production of a variety of cytokines involved in immune responses, including interleukin (IL) $-1,{ }^{40} 41$ IL-6, ${ }^{42}$ IL-2, ${ }^{43}$ IL-4, IL-5, interferon gamma, ${ }^{44}$ and transforming growth factor $\beta$ (TGF $\beta) .{ }^{45}$ The possibility of direct effects of sex hormones on the immune system is also supported by the evidence of oestrogen receptors in human synovial macrophages ${ }^{46}$ and peripheral CD8 lymphocytes, although not in the helper/inducer subset. ${ }^{47}{ }^{48}$ Androgen receptors have also been described in human thymocytes, but not in peripheral lymphocytes. ${ }^{43}{ }^{47}$ However, the binding of sex steroids was very low in these reports and studies using monoclonal antibodies to sex steroid receptors have failed to demonstrate receptors in lymphocytes. $^{3}$ Despite these interesting findings in vitro, caution should be used in their interpretation, as supraphysiological concentrations were used in most of these studies ${ }^{1215}$ and oestradiol has been shown to have variable or even opposing results upon lymphocytes, depending on concentration. ${ }^{41}$ The potential importance of carryover effects from in vivo concentrations of sex steroids upon cultured cells cannot be excluded ${ }^{49}$ and the presence of sex hormones in fetal calf serum used in cell culture is seldom accounted for.

The actions of sex hormones on the immune system in vivo may be essentially indirect, mediated by interactions with other immunomodulatory factors such as the thymus hormones, growth hormone, and prolactin. Treatment of rats with high doses of sex hormones results in marked atrophy of the thymus $^{50}$ and several lines of evidence suggest that effects of sex hormones in this gland may contribute to their actions on the immune response: a) oestrogens reduce and testosterone enhances the production of thymic hormones (such as thymulin) involved in intrathymic $\mathrm{T}$ cell differentiation; ${ }^{51}{ }^{52}$ b) $\mathrm{CD} 4$ and CD8 thymic cells are depleted by oestrogen treatment; ${ }^{53}$ and $c$ ) the thymus was shown to be indispensable for some of the immune effects of sex steroids in vivo. ${ }^{1154}$ Growth hormone and prolactin have important immunostimulatory effects. Growth hormone has been shown to stimulate delayed cutaneous hypersensitivity reactions, helper cell function of thymocytes, and haemaglutinin titres in hypophysectomized animals. ${ }^{556}$ It is considered essential for macrophage development and function. ${ }^{57}$ Female animals have greater basal concentrations and lower pulse heights of growth hormone than males, ${ }^{58}$ probably as a result of higher levels of oestrogens and progesterone. ${ }^{59} 60$ Prolactin has been demonstrated to reconstitute humoral and cell mediated immune responses in hypophysectomized animals ${ }^{55}$ and prolactin concentrations are again greater in the female as a result of the stimulating effects of oestrogens on its secretion, ${ }^{62}$ whereas dihydrotestosterone has the opposite effect. ${ }^{63}$ The influence of sex steroids on the production of thymic hormones, growth hormone, and prolactin have all been integrated in complex interaction schemes proposed to explain the gender dimorphism and influence of sex hormones in the immune system. ${ }^{464}$ Figure 1 presents a simplified diagram of these interactions.

Given the potent immunosuppressive and anti-inflammatory effects of glucocorticoids, the potential interference of sex hormones with the hypothalamus-pituitary-adrenal (HPA) axis could have particularly important implications. However, the possibility that immune effects of sex steroids in vivo may be related to interactions with the adrenal response is scarcely addressed in the literature and mostly ignored in reviews. ${ }^{3} 356465$

Glucocorticoids are the main endogenous anti-inflammatory agents in vivo, interfering with virtually every step of immune and inflammatory responses, ${ }^{66} 67$ and are commonly used in the treatment of autoimmune diseases. The physiological circadian variation of cortisol has been implicated in the diurnal fluctuation of the symptoms of RA. ${ }^{68}{ }^{69}$ Symptomatic autoimmune thyroid disease has also been reported following adrenalectomy for Cushing syndrome in women. ${ }^{70}$ The importance of endogenous glucocorticoids in the control of immune conditions is also exemplified by the increased mortality associated with adrenalectomy in rats with experimental allergic enchephalomyelitis. ${ }^{71}$ Investigations using the cotton pellet model of cartilage degradation have shown that glucocorticoids reduce the development of granulomatous tissue and induce a significant protection of cartilage..$^{72}$ 
Oestrogens Androgens, Prog (?)

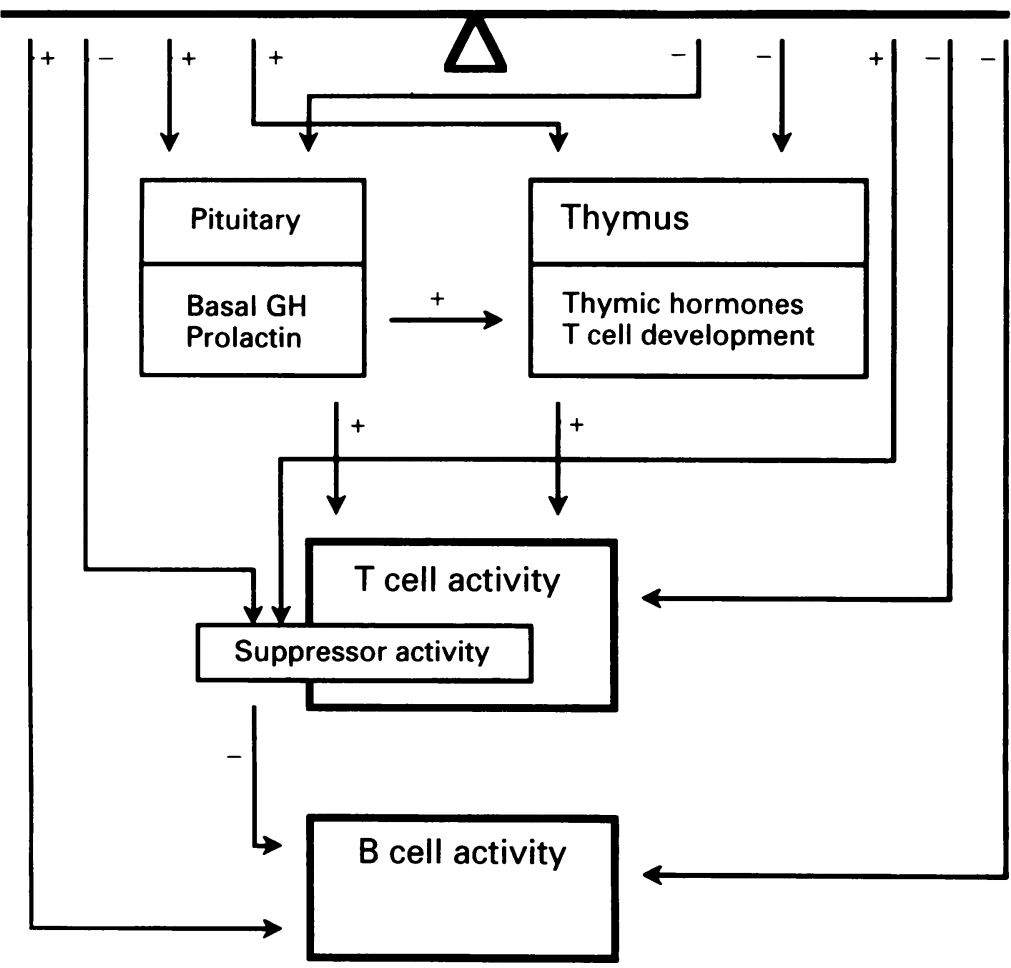

Figure 1 Proposed mechanisms for sex hormone interactions with the immune system, including direct effects on immunocompetent cells and actions upon growth hormone, prolactin, and thymus functions. Prog = progesterone; $G H=$ growth hormone.

Changes in the physiological regulation of the glucocorticoid response to inflammation could, therefore, have very important consequences for both experimental and human disease. Moreover, potential interactions of sex hormones with the glucocorticoid pathways could have far reaching implications in understanding the marked predominance of female patients in almost all autoimmune diseases.

The aim of the following sections is to review the evidence that interaction with the HPA axis may play an essential role in the immunomodulatory effects of sex hormones in vivo, and to explore the potential consequences in the pathogenesis and treatment of human disease.

\section{Sex hormones influence the HPA axis in experimental animals}

There is extensive experimental evidence demonstrating important effects of sex hormones upon glucocorticoid levels in animals, especially rodents. Female rats and mice have greater basal concentrations of circulating corticosterone, greater corticosteroidogenesis in adrenal slices ex vivo and greater circulating concentrations of transcortin, compared with males. ${ }^{74-77}$ Females have a greater glucocorticoid response to a variety of stresses, including ether anaesthesia and physical restraint. ${ }^{78-80}$

These gender differences can be directly attributed to sex hormones. Plasma concentrations of corticosterone have been shown to fluctuate during the oestrus cycle of females, being higher during the pro-oestrus (maximal oestradiol concentration). ${ }^{78} 7981$ Ovariectomy results in depressed basal and stimulated con- centrations of circulating glucocorticoids, to values similar to those of intact males. Conversely, orchidectomy results in greater corticosteroid responses to a variety of stresses. ${ }^{77808283}$ Replacement of oestradiol in ovariectomized females induces an increase in baseline and stimulated concentrations of corticosterone, while androgens have the opposite effect, reducing the glucocorticoid response to activating stimuli. 777982

Oestrogens and androgens have been shown to influence the output of adrenocorticotrophic hormone (ACTH) by the pituitary. ${ }^{83} 84$ The male and female pituitary contain similar numbers of ACTH immunoreactive cells. ${ }^{85}$ This suggests that there is a difference either in the secretion of corticotrophin releasing hormone (CRH) by the hypothalamus ${ }^{83} 8486$ or in the sensitivity of the pituitary to CRH..$^{87} 88$ In fact, both oestrogens and androgens have been shown to modulate the expression and sensitivity of glucocorticoid receptors in the hippocampus and pituitary. ${ }^{89} 90$ Recent investigations support the concept that oestrogens increase the responsiveness of the HPA axis by downregulating the negative feedback of glucocorticoids upon the hypothalamus. ${ }^{91}$ Overall, the effects of sex hormones upon the HPA axis seem to be mediated through the hypothalamic production of CRH. The possibility that sex hormones affect not only cortisol secretion but also its catabolism has not been addressed in the literature.

\section{SEX HORMONES AND GLUCOCORTICOID}

RESPONSE TO INFLAMMATION

Immune and inflammatory reactions elicit a systemic reaction which includes an increase in glucocorticoid secretion which, in turn, tends to downregulate the immune and inflammatory response. The mechanism by which inflammation activates the HPA axis is complex, but cytokines, such as IL-1, IL-6 and tumor necrosis factor alpha $(\mathrm{TNF} \alpha)$ (all detectable in serum during the acute phase response) are thought to play a central role in stimulating $\mathrm{CRH}$ production by the hypothalamus, thereby inducing glucocorticoid secretion by the adrenals. ${ }^{92} 93$ IL-1 may also directly stimulate corticosteroid production by the adrenal gland ${ }^{94}$ and ACTH is also released by activated lymphocytes during immune reactions. ${ }^{95}$

Given that sex hormones have been shown to affect the HPA axis directly but also to influence immunocompetent cells and cytokine production, the overall effect of sex steroids on the glucocorticoid response to inflammation could derive from actions in either or both sides of this equation.

We have recently performed a series of investigations addressing the issue of gender dimorphism in the HPA axis and its response to inflammation. Using cotton induced granulomatous reaction in mice as a model of chronic inflammation, we have demonstrated that the glucocorticoid response to inflammatory stimuli is affected by the same gender differences and effects of sex hormones as 


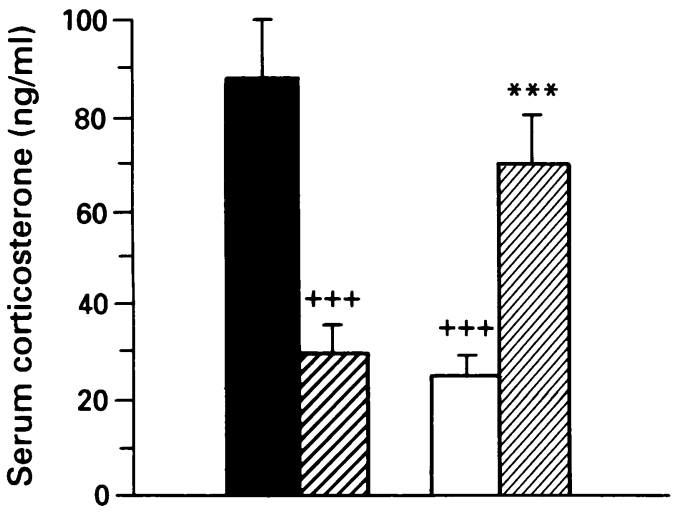

Figure 2 Effects of gender and gonadectomy on corticosterone concentrations in the presence of cotton wrapped implants in $B A L B / c$ mice. Serum was collected under stress free conditions from sham operated and gonadectomised male and female mice three weeks after they received two subcutaneous implants of cotton wrapped male femoral head cartilages from male Wistar rats. Serum corticosterone was measured. Results are expressed as mean values with SEM bars; $n=26$ to 28 for all groups.

$\nabla=$ Ovariectomy; $\square=$ orchidectomy; $=$ female sham; $\square=$ male sham ${ }^{+++} p<0.001 \mathrm{v}$ female sham:

$* * x_{p}<0.001 \mathrm{v}$ male sham (ANOVA).

previously described in response to ether and other non-inflammatory conditions. ${ }^{80}$ In the presence of granulomatous reaction, females had greater corticosterone concentrations than males, ovariectomy resulted in a diminished glucocorticoid response, while castrated males had greater glucocorticoid concentrations than intact males (fig 2). Androgen treatment decreased glucocorticoid concentrations in both males and females, while hormone replacement in castrated female mice enhanced the glucocorticoid response.

To clarify if these observations were the result of changes in cytokine release by the inflammatory tissue, we attempted to measure the serum concentrations of IL-1 in these animals. Unfortunately, these were persistently below the detection limit of our assay. However, granulomatous tissue from females had a greater content of IL- $1 \alpha$ than those from males, and orchidectomy was associated with increased concentrations of this cytokine in the inflammatory tissue from males. ${ }^{32}$ Similarly, resident peritoneal macrophages from female mice were shown to produce significantly greater amounts of IL-1 when cultured ex vivo, than those from males. ${ }^{80}$ This would suggest that modulation of cytokine production may play a role in modulation of the glucocorticoid response by sex steroids. To investigate direct effects of sex hormones on the HPA axis response to inflammatory mediators, sham operated and castrated male and female mice were injected with either saline or IL-1 $\beta$ $(12.5 \mu \mathrm{g} / \mathrm{kg})$ and serum concentrations of corticosterone were assessed two hours later.

Summary of the effects of ovariectomy and orchidectomy ( $\mathrm{v}$ sham operated female and male mice, respectively) upon inflammatory tissue and glucocorticoid response $e^{32} 8096103$

\begin{tabular}{lll}
\hline & Ovariectomy & Orchidectomy \\
\hline Inflammation-induced cartilage degradation & $\uparrow$ & $\uparrow$ \\
Granulomatous tissue IL-1 & $\uparrow$ & $\uparrow$ \\
Corticosterone response to inflammation & $\downarrow$ & $\uparrow$ \\
Corticosterone response to IL-1 & $\downarrow$ & $\uparrow$ \\
\hline
\end{tabular}

All animals injected with IL-1 had a marked increase in glucocorticoid levels and, again, the response was greater in females, decreased by ovariectomy in females and increased by male castration, reproducing the pattern seen in chronic inflammation.

Such observations show that sex hormones may change the glucocorticoid response to inflammation by directly affecting the HPA axis responsiveness to activating stimuli. Changes in the production of cytokines may also contribute to these effects. Given that cytokine production by the granulomatous tissue is also affected by endogenous glucocorticoids, discussion of these mechanisms risks a circular argument. However, interpretation of the simultaneous effects of sex hormones upon glucocorticoid concentrations, cartilage degradation and production of IL- 1 in this model may help clarify the interactions. The table summarises results from such a series of experiments. They actually lead to the concept that oestrogens and androgens affect the glucocorticoid response to inflammation, not only in opposite directions, but also through different mechanisms.

Ovariectomy resulted in increased release of IL- $1 \alpha$ by granulomatous tissue, ${ }^{96}$ which coincides with the observation that human ovariectomy is followed by an increased secretion of IL-1 and TNF $\alpha$ by peripheral blood mononuclear cells, an effect reversed by hormone replacement. ${ }^{97}$ Ovariectomy also resulted in decreased concentrations of glucocorticoid. If the actions on inflammatory cells were the primary phenomenon, an increase in glucocorticoids should be expected in response to greater concentrations of cytokines released. These observations support the concept that oestrogens influence the inflammatory process through the release of corticosteroids and that the HPA is the primary site of oestrogen influence in vivo. A similar mechanism may underly the immunosuppressive effects of female sex hormones in vivo. In fact, overall effects of glucocorticoids upon the immune system in vivo are similar to those attributed to oestrogens: they also depress $\mathrm{T}$ cell mediated responses but may actually increase immunoglobulin production at physiological concentrations. ${ }^{6698}$ Actions of oestrogens upon the thymus in vivo are also markedly similar to those of glucocorticoids. ${ }^{4}$

This hypothesis has been sparsely addressed in the literature. Toivanen $e t a l^{28}$ reported that the protective effects of oestrogens on adjuvant induced arthritis were also observed in adrenalectomised rats. However, the animals were maintained on supraphysiological concentrations of both corticosterone and oestrone, making interpretation of the results difficult. Recently the effect of oestrogen upon in vivo leucocyte production and trafficking in mice was found to be independent of endogenous glucocorticoids, ${ }^{99}$ but the authors monitored only cortisol, a steroid of minor importance in rodents. ${ }^{100}$

In contrast, the lesser production of IL-1 by granulomatous tissue and peritoneal macrophages in males suggests that androgens may 
act primarily at the inflammatory site, reducing the production of inflammatory mediators that reach and activate the hypothalamus. This is supported by the observations of an increased production of IL-1 by granulomatous tissue in castrated males, coinciding with increased circulating concentrations of glucocorticoid. If the actions of androgens on the HPA axis were the primary phenomenon, a reduction in IL-1 production and cartilage damage would be expected in response to higher levels of corticosterone in castrated males.

It is not clear how androgens bring about this effect in inflammatory tissue. In our experience, orchidectomy does not significantly influence the ex vivo release of IL-1 by resident mouse peritoneal macrophages. ${ }^{80}$ However, macrophages in an inflammatory environment may show a different response, and the complex interactions that surround these cells in inflammatory tissue provide a large number of pathways for indirect modulation, for example through $\mathrm{T}$ cells and lymphokine production. ${ }^{44}$ The possibility of direct action by androgens on these cells is supported by the recent description of androgen receptors in macrophage like cells in normal and rheumatoid synovia $^{101}$ and in cotton induced granulomatous tissue. ${ }^{32}$ This would suggest a direct anti-inflammatory role for androgens, supported by the previous findings of reduced inflammation and cartilage erosion after intralesional administration of testosterone in models of air pouch and antigen induced arthritis in mice. ${ }^{102}$ Androgens have also been shown to ameliorate RA in male patients, an effect associated with a significant increase in circulating CD8 lymphocytes. ${ }^{34}$

Overall, both female and male sex hormones have the ability to reduce immune responses and to protect cartilage from inflammation induced degradation. However, while oestrogens increase the glucocorticoid response to a variety of inflammatory and non-inflammatory stimuli, androgens have the opposite effectthey depress glucocorticoid levels. Taken together, these observations support the concept that the immunosuppressive effects of oestrogen in vivo may be mediated, at least in part, by their ability to enhance the glucocorticoid response. In contrast, similar immunosuppressive actions of androgens are probably independent from glucocorticoids. Figure 3 presents a simplified diagram of the pathways for interaction between androgens and oestrogens with the immune and glucocorticoid response proposed here.

POSSIBLE GENDER DIFFERENCES IN THE SENSITIVITY TO GLUCOCORTICOIDS

This becomes pertinent in face of the evidence that females, despite having greater levels of glucocorticoid, show a stronger immunoreactivity, produce greater amounts of IL-1 and show a greater ability to degrade articular cartilage by juxtaposed inflammatory tissue. ${ }^{32}$ This raises the possibility that glucocorticoids are more effective in male than in female animals.

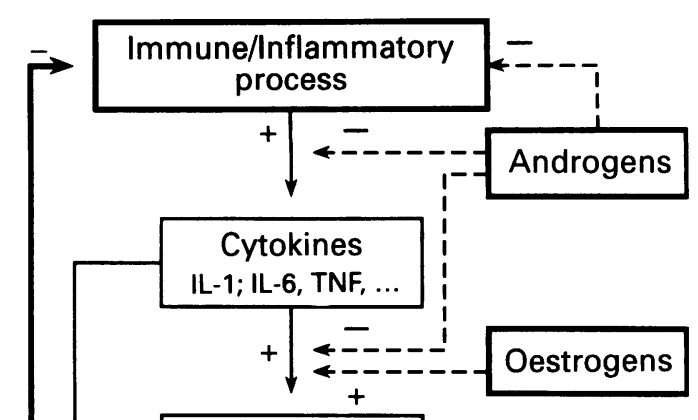
induced cartilage degradation in male and female mice. $B A L B / c$ mice received a subcutaneous implant of cotton wrapped femoral head cartilages immediately after adrenalectomy $(囚)$ or sham operation $(\square)$. Implants were recovered for analysis three weeks later and glycosaminoglycan (GAG) loss from cartilage calculated by comparison with frozen controls. ${ }^{++} p<0.01 \mathrm{v}$ female sham (ANOVA). 
IL-1 production by granulomatous tissue, despite resulting in circulating concentrations of glucocorticoids that are similar to those observed in intact females. ${ }^{80} \mathrm{We}$ also found that androgen treatment of castrated females and males resulted in significant cartilage protection and reduction of tissue IL-1, despite reduced levels of endogenous glucocorticoids. ${ }^{96}{ }^{103}$ Moreover, the facts that male animals show a weaker immune response despite having smaller concentrations of corticosteroids, and that orchidectomy results in enhanced immune response despite increasing glucocorticoid levels, suggest that endogenous androgens are more effective than endogenous corticosteroids in the control of the immune response in the male animal.

Overall females seem to be more dependent on glucocorticoids than males to control inflammatory and immune responses.

How could this be explained? It is possible that direct immunosuppressive and anti-inflammatory effects of androgens in males result in a lesser degree of inflammation and, therefore, a reduced need for endogenous glucocorticoid actions. Alternatively, it could be suggested that glucocorticoid effects are either antagonised in females or potentiated in males, probably by sex hormones.

One hypothesis encompassing these different observations is that androgens may potentiate glucocorticoid effects both at the hypothalamus and at the inflammatory site. Such actions upon the hypothalamus would justify the reduction of corticoid secretion in all of the three systems used (granuloma, IL-1, and ether) by potentiation of the negative feedback of glucocorticoids. Potential synergy at the inflammatory site could account for the protection of cartilage and decreased production of IL-1. The findings that adrenalectomy did not result in accelerated cartilage damage in males would argue against this possibility, as the adrenals are the only recognised source of glucocorticoids. However, prolonged experiments with adrenalectomy are always associated with a high mortality rate. The levels of corticosterone are not routinely assessed to verify the efficiency of the operation. This raises the possibility that the animals that survive (those for which results are included in the final analysis) are actually the ones with incomplete adrenalectomy resulting in diminished, but not absent, circulating glucocorticoids. If this is the case, it is conceivable that the potentiation of the remaining corticoids could be enough to afford cartilage protection in adrenalectomised males with intact gonads. This possibility is not taken into account in most published reports on the effects of adrenalectomy upon different experimental systems.

A potential antagonism between oestradiol and glucocorticoids is also compatible with some of the results revised above. Such antagonism is demonstrated at the hypothalamic level by the reduction of the glucocorticoid negative feedback induced by oestrogens. ${ }^{91}$ A similar effect at the inflammatory site could result in increased production of mediators, which would then act on a hypothalamus with diminished negative feedback. However, the fact that ovariectomy resulted in increased production of IL-1 by the granulomatous tissue, but decreased corticoid secretion, suggests that any potential peripheral antagonism is of less importance than the hypothalamic changes.

Evidence for direct interactions between sex hormones and glucocorticoids outside the hypothalamus is scarce. Additive or potentiating effects of androgens and corticosteroids have been demonstrated using human breast cancer cell lines, ${ }^{104}$ rat ovary granulosa cells ${ }^{105}$ and salivary glands of the rat, ${ }^{106}$ but no reports regarding immunocompetent cells could be found. Testosterone does not interact with glucocorticoid receptors. ${ }^{107} 108$ However, the glucocorticoid, androgen, and progesterone receptors share a high degree of homology in humans, ${ }^{109}$ translated into the competitive binding of molecules such as the antiandrogen, cyproterone. ${ }^{110}$ It is conceivable, therefore, that androgenic steroids, other than testosterone, could activate glucocorticoid receptors. The potency of glucocorticoid effects in the absence of interacting substances depends on the number of receptors in the target cell. ${ }^{11}$ Sex related differences in the expression of glucocorticoid receptors have been reported in rats. Females have fewer receptors in the pituitary, ${ }^{89}$ liver, and thymus ${ }^{112}$-an effect dependent on oestrogens. Androgens, including testosterone ciprionate, have been shown to increase glucocorticoid receptor expression in the hipoccampus of adrenalectomised rats. ${ }^{113}$ Dihydrotestosterone has been reported to modulate the expression of glucocorticoid receptors in the thymus and bursa of immature chickens. ${ }^{114}$ Post-receptor mechanisms could also be involved. Glucocorticoids and androgens share the same hormone response element in sensitive genes, ${ }^{115}$ suggesting that these hormones may have synergising effects upon gene expression. An example of such interactions is given by investigations of the hormone regulation of chloramphenicol acetyltransferase gene expression. ${ }^{116}$ The possible interactions between sex steroids and glucocorticoids on inflammatory and immune mechanisms seem worthy of further investigation.

\section{Potential implications of gender HPA dimorphism in human inflammatory and autoimmune diseases}

To discuss the potential importance of the sex hormone effects upon the HPA axis in human immune and inflammatory diseases, two main questions will be addressed: is there any evidence for the involvement of HPA axis dysfunction in the pathogenesis of these conditions, and is this gender dimorphism in glucocorticoid response also observed in humans? This discussion will be centred around models of experimental arthritis and human rheumatoid disease, which have been more extensively investigated. 
DISREGULATION OF ENDOGENOUS

GLUCOCORTICOIDS AND AUTOIMMUNE DISEASE A pathogenic role of HPA axis dysfunction has been clearly demonstrated in a large number of experimental models of autoimmune diseases. The Lewis LEW/N rat has a remarkable susceptibility to a large variety of experimental autoimmune diseases, in contrast with other histocompatible strains. After repeated injections of streptococcal cell walls, the female Lewis rat develops an arthritis characterised by a rapid onset acute phase followed by a chronic proliferative and destructive course which mimics human RA. ${ }^{117}$ In contrast, the histocompatible Fisher rat (F344/N) develops only a mild and transient acute phase without chronic inflammation. A series of studies have demonstrated that these differences are attributable to an innate inability of the LEW/N rat to generate an appropriate glucocorticoid response to the immune and inflammatory challenge, ${ }^{118}$ resulting from a deficient production of corticotrophin releasing hormone by the hypothalamus. ${ }^{119}$ The deficient glucocorticoid response was demonstrated in response to different activating stimuli, including IL-1. ${ }^{118}$ In contrast, the Fisher rat shows a strong glucocorticoid surge after immune challenge but develops severe experimental arthritis if treated with the steroid antagonist RU 486. ${ }^{118}$ Conversely, treatment of the LEW/N rat with physiological doses of glucocorticoids resulted in attenuated arthritis, with a pattern similar to that of the untreated Fisher rat. Similar findings have been reported regarding other autoimmune diseases and different animal species. ${ }^{120} 121$

The first suggestion that similar mechanisms could be operating in human disease was given by the finding of an increased incidence of arthritis in females with panhypopituitarism. ${ }^{122}$

Rheumatoid arthritis has been associated with abnormalities in cortisol secretion and function. Most published studies of cortisol in RA patients have reported serum concentrations within the normal range,${ }^{123-125}$ with few showing either low $^{126}$ or high ${ }^{127}$ mean serum values. However, work by Neeck et al ${ }^{128}$ demonstrated that the normal cortisol concentration in RA was inappropriate for the degree of ongoing inflammation and that the normal circadian rhythm was markedly reduced in patients with an increased erythrocyte sedimentation rate. Morand et al ${ }^{129}$ reported that mononuclear cells from RA patients produce smaller amounts of lipocortin-1 (an important mediator of glucocorticoid effects) in response to cortisol administration than do mononuclear cells from healthy controls. RA patients receiving oral glucocorticoids were also shown to have antilipocortin antibodies, resulting in resistance to the therapeutic effects of intravenous methylprednisolone. ${ }^{130}$ Peripheral lymphocytes from RA patients were found to have significantly smaller numbers of glucocorticoid receptors than those from controls. ${ }^{125}$ Abnormalities of cortisol catabolism have also been identified in lymphocytes from patients with RA and systemic lupus erythematosus (SLE). ${ }^{131}$ These findings suggest that rheumatoid patients have a peripheral defect that could lead to glucocorticoid resistance, but the possibility that these abnormalities are a consequence of the disease cannot be excluded.

Information regarding HPA axis function in $\mathrm{RA}$ is limited. Myles et al ${ }^{132}$ found normal basal and peak cortisol concentrations in response to insulin induced hypoglycaemia in patients with RA. However, the activation of the HPA axis by hypoglycaemia is probably mediated by mechanisms that differ from those involved in inflammation. The observations with the Lewis rat led to a surge of interest in the physiology of the HPA axis in humans with RA. Cash et $a l^{133}$ reported signs of mildly deficient adrenocortical response after injection of $\mathrm{CRH}$ in RA patients, but the hypothalamic function was not tested. A clearly defective glucocorticoid response to inflammatory stimuli in RA has been reported recently. ${ }^{134}$ Patients with the disease showed a diurnal cortisol secretion at the lower limit of normal compared with both normal controls and osteomyelitis patients, with a comparable degree of inflammation. Furthermore, patients with RA failed to increase cortisol concentrations after joint replacement surgery, although they presented greater concentrations of IL-1 and IL-6 than osteomyelitis patients. However, the response to $\mathrm{CRH}$ was normal in $\mathrm{RA}$, suggesting a defect in the hypothalamic production of this hormone, with normal pituitary and adrenal function. Such observations strongly suggest that RA is associated with an abnormality in the HPA axis response to inflammatory stimuli which does not result from the inflammatory process per se, as osteomyelitis patients with a similar disease duration and acute phase response showed appropriate cortisol increases. These abnormalities may be an important and hitherto unsuspected factor in the pathogenesis of rheumatoid disease. It is tempting to suggest that they are genetically determined, as in the Lewis rat-possibly in parallel with rheumatoid predisposing haplotypes.

SEX HORMONE EFFECTS ON THE HPA AXIS IN HUMANS AND THEIR POTENTIAL SIGNIFICANCE The demonstration of gender dimorphism in the HPA axis response to inflammatory stimuli in humans would represent a major, but as yet unrecognised, factor for the greater female susceptibility to autoimmune and inflammatory diseases. Although serum cortisol concentrations are usually described as similar in normal males and females, Schöneshöfer and Wagner ${ }^{135}$ observed that women in the follicular phase of the menstrual cycle had lower serum corticosteroids than those observed in the luteal phase, or in age matched males. Other indications that oestrogens stimulate glucocorticoid secretion in humans comes from the increased concentrations of cortisol seen in the late stages of pregnancy ${ }^{136}$ and in patients taking oral contraceptives. ${ }^{137} 138$ More clear evidence is given by the findings that high dose oestrogen treatment given to 
young women resulted in a marked increase in cortisol concentrations, ${ }^{139}$ while postmenopausal women were reported to have reduced concentrations of cortisol, which are increased by hormone replacement. ${ }^{140141}$ Androgens have also been shown to decrease glucocorticoid secretion in humans. In males with prostate carcinoma, both castration and oestradiol treatment resulted in increased circulating cortisol. ${ }^{142} 143$ Testosterone treatment also resulted in decreased cortisol concentrations in ovariectomised humans. ${ }^{144}$ These observations are in agreement with the experimental findings reviewed above.

The cortisol response to ACTH and CRH are described as similar in both sexes. ${ }^{145}$ However, gender differences and effects of sex steroids in the hypothalamus, as suggested by experimental evidence, would not be detected by these tests. The responses to ACTH and CRH in RA patients reported by Chikanza et $a l^{134}$ were not analysed separately for each sex. No reports were found regarding cortisol response to CRH in male and female animals and, although the male LEW/N rat is relatively resistant to streptococcal cell wall arthritis, its glucocorticoid response to the immune challenge has not been tested. The only standard investigation of HPA axis function in humans that includes the hypothalamus is the hypoglycaemia test. Responses to this test are also reportedly similar between the genders. ${ }^{145}$ However, hypothalamic secretion of CRH can be activated by a variety of different mechanisms which will depend on the nature of the stimulus involved. ${ }^{146}$ Gender differences may exist in response to inflammatory stimuli activating the HPA axis by a different pathway, as suggested by findings that patients with an impaired corticosteroid response to hypoglycaemia may have a normal response to surgery or infection. ${ }^{147}$

Bliss et al $^{148}$ proposed the assessment of the glucocorticoid response to 'bacterial pyrogens' as a method to investigate the HPA axis in humans and it is almost certain that the response to this pyrogen is mediated by IL-1 and other cytokines, offering an opportunity to study the HPA axis activation by inflammatory mediators. Serum glucocorticoids achieved maximal values three hours after the injection-a timing compatible with cytokine mediation. None of the published reports using this method analysed the response of normal males and females separately, and only a few offer results in normal controls. However, in the report by Staub et al ${ }^{149}$ the corticosteroid response to pyrogen was significantly greater in two normal females than in the five males tested (means $387 v 261 \mu \mathrm{g} / \mathrm{l}$ two hours after injection; $p<0.05$ by Mann-Whitney $U$ test), while there were no differences in the response to vasopressin or insulin induced hypoglycaemia. However, Jenkins and Elkington, ${ }^{150}$ whose study included seven male and seven female normal controls showed no gender differences in the response to pyrogen or metyrapone.

Overall, there is strong evidence that sex hormones affect glucocorticoid secretion in humans in a pattern similar to that observed in experimental animals. The hypothesis that male and female humans have a different glucocorticoid profile in response to immune and inflammatory stimuli remains untested, but could have important implications in understanding the preponderance of females in most autoimmune disease populations.

There is now good evidence to suggest that female animals are more dependent on the glucocorticoid response than males to control the immune and inflammatory processes, probably because of protective effects of androgens in males. If this is shown to be true in humans, a defect in glucocorticoid response (as reported in RA), perhaps genetically determined, would be expected to contribute to a greater susceptibility to immune and inflammatory processes in females. In contrast, gonadal insufficiency would be expected to play a more important role in males, in keeping with the observations of hypogonadism in male RA and SLE patients and greater incidence of the disease with ageing and declining concentrations of androgens. Such interactions would also have important implications for the therapeutic approach to autoimmune and inflammatory diseases.

1 Ansar Ahmed S, Penhale W J, Talal N. Sex hormones, immune responses, and autoimmune diseases. Mechimmune responses, and autoimmune diseases. Mechanisms of

2 Felson D T. Epidemiology of the rheumatic diseases. In: McCarty D J, Koopman W J, eds. Arthritis and allied conditions. A textbook of rheumatology, 12th edn. Philadelphia: Lea \& Febiger, 1993; 17-48.

3 Ansar Ahmed S, Talal N. Sex hormones and the immune system-part 2. Animal data. Baillière's Clin Rheumatol 1990; 4: 13-31.

4 Grossman C. Possible underlying mechanisms of sexual dimorphism in the immune response, fact and hypothesis. f Steroid Biochem 1989; 34: 241-51.

5 Schuurs A H W M, Verheul H A M. Effects of gender and sex steroids on the immune response. $\mathcal{f}$ Steroid Biochem 1990; 35: 157-72.

6 Butterworth M B, McClellan B, Alansmith M. Influence of sex on immunoglobulin levels. Nature 1967; 214: 1224-5.

7 Brick J E, Wilson D A, Walker S E. Hormonal modulation of responses to thymic independent and thymicdependent antigens in autoimmune NZB/W mice. f Immunol 1985; 136: 3693-8.

8 Graff R J, Lappe M A, Snell G D. The influence of the gonads and adrenal glands on the immune response to skin grafts. Transplantation 1969; 7: 105-11.

9 Dresser D W. Specific inhibition of antibody production. I. Protein over-loading paralysis. Immunology 1962; 5: 161-8.

10 Blazkovec A A, Orsini M W. Ontogenetic aspects of sexual dimorphism and the primary immune response to sheep erythrocytes in hamster from prepuberty through senescence. Int Arch Allergy Appl Immunol 1976; 50: 55-67.

11 Castro J E. Orchidectomy and the immune response. II Response of orchidectomized mice to antigens. Proc $R$ Soc Biol (Lond) 1974; 185: 437-51.

12 Stimson $\mathrm{W} \mathrm{H}$, Hunter I C. An investigation into the immunosuppressive properties of estrogen. $\mathcal{F}$ Endocrinol 1976; 69: 42-3P

13 Paavonen T. Hormonal regulation of lymphocyte function. Med Biol 1987; 65: 229-40.

14 Ablin R J, Bhatti R A, Guinan P D, Khin W. Modulating effects of estrogen on immunological responsiveness. II. Suppression of tumour-associated immunity in patients with prostatic carcinoma. Clin Exp Immunol 1979; 38: with pros

15 Kincl F A, Ciaccio L A. Suppression of immune response by progesterone. Endocrinologia Experimentalis 1980; 14: 27-32.

16 Jansson L, Holmdahl R. The Y chromosome-linked 'autoimmune accelerating' yaa gene suppresses collageninduced arthritis. Eur f Immunol 1994; 24: 1213-7.

17 Roubinian J R, Papoian R, Talal N. Androgenic hormone modulate autoantibody responses and improve survival in murine lupus. $\mathcal{F}$ Clin Invest 1977 ; 59: 1066-70.

18 Ansar Ahmed S, Talal N. Sex steroids, sex steroid receptors and autoimmune diseases. In: Sheridan P S, et al, eds. Steroid receptors and disease: cancer, autoimmune, bone and circulatory disorders. New York: Marcel Dekker, $1988 ; 289-316$. 
19 Jungers $\mathrm{P}$, Dougados M, Pelissier $\mathrm{C}$ et al. Influence of ora contraceptive therapy on activity of systemic lupus erythematosus. Arthritis Rheum 1982; 25: 618-23.

20 Angello V, Parisier J, Gell J, Gelfand J, Turksoy R N Preliminary observations on danazol therapy of systemic lupus erythematosus. $\mathcal{F}$ Rheumatol 1983; 10: 682-7.

21 Ansar Ahmed S, Penhale W J. The influence of testosterone on the development of autoimmune thyroiditis in thymectomized and irradiated rats. Clin Exp Immuno 1982; 48: 367-74

22 Okayasu I, Kong Y M, Rose N R. Effect of castration and sex hormones on experimental autoimmune thyroiditis. Clin Immunol Immunopathol 1981; 20: 240-5.

23 Steinberg A D, Smathers P A, Boegel W B. Effects of sex hormones on autoantibody production by NZB mice and modification by environmental factors. Clin Immunol Immunopathol 1980; 17: 562-72.

24 Milch D R, Gershwin M E. Murine autoimmune hemolytic anemia via xenogeneic erythrocyte immunization. III. Differences of sex. Clin Immunol Immunopathol 1981; 18 $1-11$

25 Ariga $\mathrm{H}$, Edwards J, Sullivan D A. Androgen control of autoimmune expression in lacrimal gland of MRL-MP/ lpr-lpr mice. Clin Immunol Immunopathol 1989; 53: 499-508.

26 Allen J B, Blatter B, Calandra G B, Wilder R L. Sex hormonal effects on the severity of streptococcal cell wallinduced polyarthritis in the rat. Arthritis Rheum 1983; 26: $560-3$.

27 Larson P, Holmdahl R. Estrogen-induced suppression of collagen arthritis. II. Treatment of rats suppresses development of arthritis but does not affect the antitype II collagen humoral response. Scand f Immunol 1987 27: 579-83.

28 Toivanen P, Sukala H, Laiho P, Paavilaines T. Suppression of adjuvant arthritis by estrone in adrenalectomized and ovariectomized rats. Experientia 1967; 23: 560-1.

29 Arnason B G, Richman D P. Effect of oral contraceptives on experimental demyelinating disease. Arch Neurol 1969; 21: $103-6$.

30 Willoughby D A, Ryan G B. Evidence for a possible endogenous antigen in chronic inflammation. $\mathscr{f}$ Pathol 1970; 101: 233-9.

31 De Brito F B, Moore A R, Holmes M J G, Willoughby D A. Cartilage damage by a granulomatous
reaction in a murine species. $B r \mathcal{F}$ Exp Path 1987; 68: reaction

32 Da Silva J A P, Larbre J-P, Seed M P, et al. Gender differences in inflammation-induced cartilage degradation in rodents. The influence of sex steroids. $\mathcal{F}$ Rheumato 1994; $21: 330-7$.

33 Hall G M, Daniels M, Huskisson E C, Spector T D. A randomized controlled trial of the effect of hormone replacement therapy on disease activity in postmenopausal rheumatoid arthritis. Ann Rheum Dis 1994 53: 112-6.

34 Cutolo M, Balleari E, Giusti M, Intra E, Accardo S. Androgen replacement therapy in male patients with Androgen replacement therapy in male patients

35 Grossman C J, Roselle G A, Mendenhall C L. Sex steroid regulation of autoimmunity. $\mathcal{F}$ Steroid Biochem Mol Biol 1991; 40: 649-59.

36 Paavonen T, Andersson L C, Adlercreutz H. Sex hormone regulation of in vitro immune response. Estradio enhances human B-cell maturation via inhibition of suppressor $\mathrm{T}$ cells in pokeweed mitogen-stimulated cultures. $\mathcal{F} \operatorname{Exp}$ Med 1981; 154: 1935-45.

37 Wyle F A, Kent J R. Immunosuppression by sex steroid hormones. I. The effect upon PHA- and PPD-stimulated lymphocytes. Clin Exp Immunol 1977; 27: 407-15.

38 Hou J, Zheng W F. Effect of sex hormones on NK and ADCC activity of mice. Int $\mathcal{F}$ Immunopharmacol 1988; 10: 15-22.

39 Holdstock G, Chastenay B F, Krawitt E L. Effect of restosterone, testosterone, oestradiol and progesterone on

40 Polan M L, Daniele A, Kuo A. Gonadal steroids modulate human monocyte interleukin-1 (IL-1) activity. Fertil Steri 1988; 49: 964-8.

41 Hu S-K, Mitcho Y L, Rath N C. Effect of estradiol on interleukin 1 synthesis by macrophages. Int $\mathcal{f}$ Immunopharmacol 1988; 10: 247-52.

42 Guerne P-A, Carson D A, Lotz M. IL-6 production by human articular chondrocytes. Modulation of its synthesis by cytokines, growth factors, and hormones in vitro. F Immunol 1990; 144: 499-505.

43 Kovacs W J, Olsen N J. Androgen receptors in human thymocytes. F Immunol 1987; 139: 490-3.

44 Araneo B A, Dowell T, Diegel M, Daynes R A Dihydrotestosterone exerts a depressive influence on the pihydrotestosterone exerts a depressive influence on the production of interleukin-4 (IL-4), IL-5 and gammainterferon but not

45 Komm B S, Terpening C M, Benz D J, et al. Estrogen binding, receptor mRNA, and biologic response in

46 Cutolo $\mathrm{M}$, Accardo S, Villaggio $\mathrm{B}$, et al. Presence of estrogen-binding sites on macrophage-like synoviocytes and CD8+, CD29+, CD45RO+ lymphocytes in norma and rheumatoid synovium. Arthritis Rheum 1993; 36: 1087-97.

47 Cohen J H M, Danel L, Cordier G, et al. Sex steroid receptors in peripheral $\mathrm{T}$ cells: absence of androgen receptors and restriction of estrogen receptors
positive cells. F Immunol 1983; 131: 2767-71.
48 Stimson W H. Estrogen and human $T$ lymphocytes: presence of specific receptors in the T-suppressor/ presence of specific receptors in the T-suppres

49 Glover J F, Irwin J T, Darbre P D. Interaction of phenol red with estrogenic and antiestrogenic action on growth of human breast cancer cells ZR-75-1 and T-47-D Cancer Res 1988; 48: 3693-7.

50 Sobhon P, Jirasattham C. Effects of sex hormones on the thymus and lymphoid tissue of ovariectomized rats. Acta Anatomica 1974; 89: 211-25.

51 Allen L S, McClure J E, Goldstein A L, Barkley M S, Michael S D. Estrogen and thymic hormone interactions in

25-37.

Hall R N, Goldstein A L. Endocrine regulation of host immunity. In: Fenichel R L, Chirigos M A, eds. Immunomodulation agents and their mechanisms. New York: Marcel Dekker, 1984: 533-63.

53 Screpanti I, Morrone S, Meco D, et al. Steroid sensitivity of thymocyte subpopulations during intrathymic differentiation. Effects of $17 \beta$ estradiol and dexamethasone on subsets expressing $\mathrm{T}$ cell antigen receptor or IL-2 receptor. F Immunol 1989; 142: 3378-83.

54 Stimson W H, Hunter I C. Estrogen-induced immunoregulation mediated through the thymus. 7 Clin Lab Immunol 1980; 4: 27-33.

55 Nagy E, Berczi I, Friesen H G. Regulation of immunity in rats by lactogenic and growth hormones. Acta in rats by lactogenic and growth

56 Pandian M R, Talwar G P. Effect of growth hormone on the metabolism of thymus and on the immune response against sheep erythrocytes. F Exp Med 1971; 134: 1095-113.

57 Wilder R L, Sternberg E M. Neuroendocrine hormonal factors in rheumatoid arthritis and related conditions. Curr Opin Rheumatol 1990; 2: 436-40.

58 Jansson J-O, Ekberg S, Isaksson O G P, Eden S. Influence of gonadal steroids on age- and sex-related secretory patterns of growth hormone in the rat. Endocrinology 1984; 114: 1287-94.

59 Plotnick L P, Thompson R G, Beitins I, Blizzard R M Integrated concentrations of growth hormone correlated with stage of puberty and estrogen levels in girls. $f$ Clin with stage of puberty and estrogen

60 Fukata J, Martin J B. Influence of sex steroid hormones on rat growth hormone-releasing factor and somatostatin in dispersed pituitary cells. Endocrinology 1986; 119: 2256-61.

61 Berczi I, Nagy E, Kovacs K, Horvath E. Regulation of humoral immunity in rats by pituitary hormones. Acta Endocrinol (Copenh) 1981; 98: 506-13.

62 Shull J, Gorski J. Estrogen regulation of prolactin gene ranscription in vivo; paradoxical effect of $17 \beta$-estradiol dose. Endocrinology 1989; 124: 279-85.

63 Giguere V, Meunier H, Veilleux R, Labrie F. Direct effect of sex steroids on prolactin release at the anterior pituitary level; interactions with dopamine, thyrotropin-releasing hormone and siobutyl-methyl-xanthine. Endocrinology 1982; 111: 857-62.

64 Golsteyn E J, Fritzler M J. Review: the role of the thymushypothalamus-pituitary-gonadal axis in normal immune processes and autoimmunity. $f$ Rheumatol 1987; 14 982-90.

65 Bhalla A K. Hormones and the immune response. Ann Rheum Dis 1989; 48: 1-6.

66 Cupps T R, Fauci A S. Corticosteroid-mediated immunoregulation in man. Immun Rev 1982; 65: 133-55.

67 Sternberg E M, Wilder $\mathrm{R}$ L. Corticosteroids. In McCarty D J, Koopman W J, eds. Arthritis and allied conditions. $A$ textbook of rheumatology, $12 \mathrm{th}$ edn. Philadelphia: Lea \& Febiger, 1993: 665-82.

68 Saldanha C, Touzas G, Grace E. Evidence for the antiinflammatory effects of normal circulating plasma cortisol. Clin Exp Rheumatol 1986; 4: 365-6.

69 Kirkham B W, Panayi G S. Diurnal periodicity of cortisol secretion, immune reactivity and disease activity in heumatoid arthritis: implications for steroid treatment. Brf Rheumatol 1989; 28: 154-7.

70 Takasu N, Komiya I, Nagasawa Y, Asawa T, Yamada T. Exacerbation of autoimmune thyroid dysfunction after unilateral adrenalectomy in patients with Cushing's syndrome due to an adrenocortical adenoma. $N$ Engl $f$ Med 1990; 322: 1708-12.

71 Macphee I A M, Antoni F A, Mason D W. Spontaneous recovery of rats from experimental allergic encephalomyelitis is dependent on regulation of the immune system by endogenous adrenal corticosteroids. 7 Exp Med 1989; 169: 431-45.

72 De Brito F B, Holmes M J G, Carney S L, Willoughby D A. Drug effects on a novel model of Willoughby D A. Drug effects on a novel model of connective

73 Bottomley K M K, Griffiths R J, Rising T J, Steward A A modified air pouch model for evaluating the effects of compounds on granuloma induced cartilage degradation. Br f Pharmacol 1988; 93: 627-35.

74 Kitay J I. Pituitary-adrenal function in the rat after gonadectomy and gonadal hormone replacement. Endocrinology 1963; 73: 253-60.

75 Gala R, Westphal U. Further studies on the corticosteroidbinding globulin in the rat: proposed endocrine control. Endocrinology 1966; 79: 67-76.

76 Allen-Rowlands C F, Allen J P, Greer M A, Wilson M Circadian rhythmicity of ACTH and corticosterone in the rat. $\mathcal{F}$ Endocrinol Invest 1980; 4: 371-7. 
77 Lesniewska B, Miskowa B, Nowak M, Malendowicz L K Sex differences in adrenocortical structure and function. XXVII. The effect of ether stress on ACTH and costicosterone in intact, gonadectomized, and testosteroneor estradiol-replaced rats. Res Exp Med 1990; 190: 95-103.

78 Baron S, Brush F R. Effects of acute and chronic restrain and estrus cycle on pituitary adrenal function in the rat. Horm Behav 1979; 12: 218-24.

79 Viau V, Meaney $M$ J. Variations in the hypothalamicpituitary-adrenal response to stress during the estrous cycle in the rat. Endocrinology 1991; 129: 2503-11.

80 Da Silva J A P, Peers S H, Perretti M, Willoughby D A. Sex steroids affect glucocorticoid response to chronic inflammation and to interleukin-1. F Endocrinol 1993; 136: 389-97.

81 Nichols D J, Chevins P F D. Plasma corticosterone fluctuations during the oestrus cycle of the house mouse. Experientia 1981; 37: 319-20.

82 Kitay J I. Effects of estrogen and androgen on the adrena cortex of the rat. In: Kerns K W, ed. Functions of the adrenal cortex, vol 2. New York: Appleton-Century-Crofts, 1968: 775-811.

83 LeMevel J C, Abitbol S, Beraud G, Maniey J. Temporal changes in plasma adrenocorticotropin concentration after repeated neurotropic stress in male and female mice. Endocrinology 1979; 105: 812-7.

84 Buckingham J C. Effect of adrenocortical and gonada steroids on the secretion in vitro of corticotrophin and its hypothalamic releasing factor. F Endocrinol 1982; 93: hypotha 32 .

85 Malendowicz L K, Stachowiak A, Zabel M. Sex differences in adrenocortical structure and function. XXV. Quantitative analysis of ACTH-immunoreactive cells in the anterior pituitary of gonadectomized and gonadal hormone replaced male and female rats. Exp Clin Endocrinol 1987; 90: 1-8

86 Haas D A, George S R. Estradiol and ovariectomy decreases CRF synthesis in hypothalamus. Brain Res Bull 1989; 23: 215-8.

87 Coyne M D, Kitay J I. Effect of orchiectomy on pituitary secretion of ACTH. Endocrinology 1971; 89: 1024-8.

88 Miskowiak B, Lesniewska B, Nowak M, Malendowicz L K. Studies on the hypothalamo-pituitary corticoliberin
system. V. The effects of gonadectomy and sex hormones on plasma ACTH and on the reactivity of the anterior on plasma ACTH and on the reactivity of the anterior
pituitary gland to CRF. Exp Clin Endocrinol 1988; 92: pituitary

89 Turner B B. Sex difference in glucocorticoid binding in rat pituitary is estrogen dependent. Life Sci 1990; 46: 1399-406.

90 Ahima R S, Lawson A N L, Osei S Y S, Harlan R E. Sexual dimorphism in regulation of Type II corticosteroid receptor immunoreactivity in the rat hippocampus. Endocrinology 1992; 131: 1409-16.

91 Burgess L H, Handa R J. Chronic estrogen-induced alterations in adrenocorticotropin and corticosterone secretion, and glucocorticoid receptor-mediated functions in female rats. Endocrinology 1991; 131: 1261-9.

92 Besedowsky H O, Del Rey A, Klusman I, Furukawa H, Monge Arditi G, Kabiersch A. Cytokines as modulators Monge Arditi G, Kabiersch A. Cytokines as modulators
of the hypothalamo-pituitary-adrenal axis. $\mathcal{F}$ Steroid of the hypothalamo-pituitary-adren

93 Imura H, Fukata J, Mori T. Cytokines and endocrine function: an interaction between the immune and neuroendocrine systems. Clin Endocrinol 1991; 35: 107-15.

94 Roh M S, Drazenovich K A, Barbose J F, Dinarello C A, Cobb C F. Direct stimulation of the adrenal cortex by interleukin-1. Surgery 1987; 102: 140-6.

95 Smith E M, Highes T K, Leung M K, Stefano G B. The production and action of ACTH-related peptides in production and action of ACTH-related peptides in

96 Da Silva J A P, Colville-Nash P, Spector T D, Scott D L, Willoughby D A. Inflammation-induced cartilage Willoughby $\mathrm{D} A$. Inflammation-induced cartilage degradation in female rodents: protective rol

97 Pacifici R, Brown C, Puscheck E, et al. Effect of surgical menopause and estrogen replacement on cytokine release from human blood mononuclear cells. Proc Natl Acad Sci USA 1991; 88: 5134-8.

98 Emilie D, Crevon M C, Auffredou M T, Galanaud P. Glucocorticosteroid-dependent synergi between interleukin-1 and interleukin-6 for human B lymphocyte differentiation. Eur f Immunol 1988; 18: 2043-7.

99 Josefsson E, Tarkowski A, Carlsten H. Anti-inflammatory properties of estrogen. I. In vivo suppression of leucocyte production in bone marrow and redistribution of peripheral blood neutrophils. Cell Immunol 1992; 142: peripheral $67-78$.

100 Shimizu K, Amagaya S, Ogihara Y. Analysis of corticosterone in the serum of mice and rats, using high 272: $170-4$.

101 Cutolo M, Accardo S, Villagio B, et al. Evidence for the presence of androgen receptors in the synovial tissue of rheumatoid arthritis patients and healthy controls. Arthritis Rheum 1992; 35: 1007-15.

102 Steward A, Bayley D L. Effects of androgens in models of rheumatoid arthritis. Agents Actions 1992; 35: 268-72.

103 Da Silva J A P, Larbre J-P, Spector T D, Perry L A, Scott D L, Willoughby D A. Protective effect of androgens against inflammation-induced cartilage degradation 285 .
104 Simard J, de Launoit Y, Haagensen D A, Labrie F. Additive stimulatory action of glucocorticoids and androgens on basal and estrogen-repressed apolipoprotein-D messenger ribonucleic acid levels and secretion in human breast cancer cells. Endocrinology 1992; 130: 1115-21.

105 Jia X C, Ny T, Hsueh A J. Synergistic effects of glucocorticoids and androgens on the hormonal induction of tissue plasminogen activator activity and messenger
ribonucleic acid levels in granulosa cells. Mol Cell ribonucleic acid levels in

106 Antakly T, Zhang C X, Sarrieau A, Raquidan D. Cellspecific expression of the glucocorticoid receptor within granular convoluted tubules of the rat submaxillary gland. Endocrinology 1991; 128: 617-22.

107 Cidlowski J A, Cidlowski N B. Regulation of glucocorticoid receptors by glucocorticoids in cultured corticoid receptors by glucocorticoids in 2 .

108 DiBattista J A, Martel-Pelletier J, Wosu L, Sandor T, Antakly T, Pelletier J-P. Glucocorticoid receptor mediated inhibition of interleukin-1 stimulated neutral metalloprotease synthesis in normal human chondrocytes. f Rheumatol 1991; 72: 316-26.

109 Brinkmann A O, Faber P W, van Rooij H C J, et al. The human androgen receptor: domain structure, genomic organization and regulation of expression. $\mathcal{f}$ Steroid Biochem 1989; 34: 307-10.

110 Gaillard-Moguilewsky M. Pharmacology of antiandrogens and value of combining androgen suppression with antiandrogen therapy. Urology 1991; 37 (suppl 2): 5-12.

111 Catt K J, Harwood J P, Agullera J, Dufau M L. Hormonal regulation of peptide receptors and target cell responses. regulation of peptide recepto

112 Endres D B, Milholland R J, Rosen F. Sex differences in the concentrations of glucocorticoid receptors in rat liver and thymus. $\mathcal{F}$ Endocrinol 1979; 80: 21-6.

113 Ahima R S, Harlan R E. Regulation of glucocorticoid immunoreactivity in the rat hipoccampus by androgenicanabolic steroids. Brain Res 1992; 585: 311-4.

114 Coulson P, Skafar D, Seaver S, Thornthwaite J. Dihydrotestosterone modulation of glucocorticoid receptor levels in thymus and Bursa de Fabricius cells in immature chickens. In: Proceedings of the Endocrine Society 63rd Annual Meeting, 1981: 255.

115 Beato M, Chalepakis G, Schauer M, Slater E P. DNA regulatory elements for steroid hormones. $\mathcal{f}$ Steroid Biochem 1989; 32: 737-47.

116 Adler A J, Scheller A, Hoffman Y, Robins D M. Multiple components of a complex androgen-dependent enhancer. Mol Endocrinol 1991; 5: 1587-96.

117 Wilder R L, Calandra G B, Garvin A J, Wright K D, Hansen $C$ T. Strain and sex variation in the susceptibility to streptococcal cell wall-induced polyarthritis in the rat. Arthritis Rheum 1982; 25: 1064-72.

118 Sternberg E M, Hill J M, Chrousos G, et al. Inflammatory mediator-induced hypothalamic-pituitary-adrenal axis activation is defective in stretococcal cell wall arthritissusceptible Lewis rats. Proc Natl Acad Sci USA 1989; 86: 2374-8.

119 Sternberg E M, Scott Young W III, Bernardini R, et al. A central nervous system defect in biosynthesis of A central nervous system defect in biosynthesis of corticotropin-releasing hormone is associated with Lewis rats. Proc Natl Acad Sci USA 1989; 86: 4771-5.

120 Schauenstein K, Fässler R, Dietrich H, Schwarz S, Krömer G, Wick G. Disturbed immune-endocrine communication in autoimmune disease: lack of corticosterone response to immune signals in obese strain chickens with spontaneous autoimmune thyroiditis. f Immunol 1987; 139: 1830-3.

121 Mason D. Genetic variation in the stress response: susceptibility to experimental allergic encephalomyelitis and implications for human inflammatory disease. Immunol Today 1991; 12: 57-60.

122 Sugar M. Arthritis and panhypopituitarism. 7 Clin Endocrinol Metab 1953; 13: 118-21.

123 Spector T D, Perry L A, Tubb G, Silman A J, Huskisson E C. Low free testosterone levels in rheumatoid arthritis. Ann Rheum Dis 1988; 47: 65-8.

124 Aroso Dias A, Lopes Vaz A, Hargreaves $M$, et al. Biomarks in secondary osteoporosis. Clin Rheumatol 1989; 8 (suppl 2): 89-94

25 Schlaghecke R, Kornely E, Wollenhaupt J, Specker C. Glucocorticoid receptors in rheumatoid arthritis. Arthritis Rheum 1992; 35: 740-4

126 Hedman M, Nilsson E, de la Torre B. Low blood and synovial levels of sulphoconjugated steroids in rheumatoid arthritis. Clin Exp Rheumatol 1992;19: 25-30.

127 Spector T D, Perry L A, Tubb G, Huskisson E C. Androgen status of females with $\mathrm{RA}, \mathrm{Br} f$ Rheumatol 1987; 25: 316-8.

128 Neeck G, Federlin K, Graef V, Rusch D, Schmidt K L. Adrenal secretion of cortisol in patients with rheumatoid Adrenal secretion of cortisol in patients

129 Morand E F, Jefferiss C M, Goulding N J, Maddison P J Induction of lipocortin-1 by glucocorticoids is impaired in rheumatoid arthritis [abstract]. Arthritis Rheum 1991; 34 (suppl 9): S155.

130 Podgorski M R, Goulding N J, Hall N D, Flower R J, Maddison $\mathrm{P}$ J. Autoantibodies to lipocortin-1 are associated with impaired glucocorticoid responsiveness in rheumatoid arthritis. $\mathcal{F}$ Rheumatol 1992; 19: 1668-71.

31 Klein A, Buskilla D, Gladman D, Bruser B, Malkin A Cortisol catabolism by lymphocytes of patients with systemic lupus erythematosus and rheumatoid arthritis. f Rheumatol 1990; 17: 30-33. 
132 Myles A B, Schiller L F, Glass D, Daly J R. Single daily dose corticosteroid treatment. Ann Rheum Dis 1976; 35: 73-6.

133 Cash J M, Crofford L J, Gallucci W T, et al. Pituitaryadrenal axis responsiveness to ovine corticotropin releasing hormone in patients with rheumatoid arthritis treated with low-dose prednisolone. $\mathcal{F}$ Rheumatol 1992 19: $1692-6$

134 Chikanza I C, Petrou P, Kingsley G, Chrousos G Panayi G S. Defective hypothalamic response to immune and inflammatory stimuli in patients with rheumatoid arthritis. Arthritis Rheum 1992; 35: 1281-8.

135 Schöneshöfer $M$, Wagner G C. Sex differences in corticosteroids in man. 7 Clin Endocrinol Metab 1977; 45: 814-7.

136 Nolton W E, Rueckert P A. Elevated free cortisol index in pregnancy. Possible regulatory mechanism. Am $\mathrm{f}$ Obstet Gynecol 1981; 139: 492-8.

137 Bulbrook R D, Herian M, Tong J L, Hayward J L Swain M C, Wang D Y. Effects of steroidal contraceptives on levels of plasma androgen sulphates and cortisol. on levels of plasma

138 Meulenberg P M M, Ross H A, Swinkels L M J W Benraad T J. The effects of oral contraceptives on plasmafree and salivary cortisol and cortisone. Clin Chim Acta 1987; 165: 379-85.

139 Zachman M, Manella B, Eiholzer U, Bucher H, Prader A. Influence of estrogen in high and low doses on plasm steroid concentrations in girls with tall stature and Turner syndrome. Acta Endocrinol (Copenh) 1984; 106: 368-73.

140 Helgason S, Carlstrom K, Damber M G, Damber J E Selstam $G$, von Scoult $z$ B. Effects of various estrogens on circulating androgens and cortisol during replacement . Maturitas 1981; 3: $301-8$.
141 Tazuke S, Khaw K T, Barrett-Connor E. Exogenous estrogens and endogenous sex hormones. Medicine (Baltimore) 1992; 71: 44-51.

142 Pousette A, Carlstrom K, Stege R. Androgen during different modes of endocrine treatment of prostatic different modes of endocrine

143 Carlstrom K, Stege R. Adrenocortical function in prostatic cancer patients: effects of orchidectomy or different modes of estrogen treatment on basal steroid levels and on the response to exogenous adrenocorticotropic hormone. Urol Int 1990; 45: 160-3.

144 de Weerdt O, Gooren L J. Patterns of serum cortisol levels in ovariectomized females with and without androgen administration. Horm Metab Res 1992; 24: 82-4.

145 Orth D N, Kovacs W J, DeBold C R. The adrenal cortex. In: Wilson V, Foster D W, eds. Williams textbook of endocrinology, 8th edn. Philadelphia: W B Saunders Co, 1992: 489-619.

146 Gillies G, Linton E, Lowry P. The physiology of corticotropin-releasing factor. In: De Groot $\mathrm{LJ}$, et al, eds. Endocrinology,

147 Wynn V. The assessment of hypothalamic-pituitaryadrenal function in man. Memoirs of the Society for Endocrinology 1968; 17: 213-36.

148 Bliss E L, Migeon C J, Eik-Nes K, Sandberg A A Samuels L T. The effects of insulin, histamine, bacteria pyrogen and the antabuse-alcohol reaction upon the levels of 17-hydroxycorticosteroids in the peripheral blood of man. Metabolism 1954; 3: 493-501.

149 Staub J J, Jenkins J S, Ratcliffe J G, Landon J. Comparison of corticotrophin and corticosteroid response to lysine-vasopressin, insulin, and pyrogen in man. BMF 1973;1: 267-9.

150 Jenkins J S, Elkington S G. Metyrapone and pyrogen in the assessment of pituitary-adrenal function after removal of pituitary adenoma. Lancet 1964; 2: 991-4. 